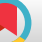

\title{
Assessment of Clinical Communication Skills of Medical Students Through the Simulated Patient Approach
}

\author{
Nilesh Chavda ${ }^{1,}{ }^{,}$, Priti Solanky ${ }^{2}$, Jatin V Dhanani (iD) ${ }^{1}$, Aashal Shah ${ }^{1}$, Nirav Patel ${ }^{1}$ and Sunilkumar \\ Bhadiyadara $^{3}$ \\ ${ }^{1}$ Pharmacology Department, GMERS Medical College, Valsad, Gujarat, India \\ ${ }^{2}$ Department of Community Medicine, GMERS Medical College, Valsad, Gujarat, India \\ ${ }^{3}$ Pharmacology Department, GMERS Medical College, Vadnagar, India \\ "Corresponding author: Associate Professor, Pharmacology Department, GMERS Medical College, Valsad, Gujarat, India. Email: drnileshchavdamd@gmail.com
}

Received 2020 August 23; Revised 2020 November 17; Accepted 2020 November 17.

\begin{abstract}
Background: Good communication skill is as crucial for the medical practitioner as medical knowledge for better patient outcome. Incorporating simulated patients for teaching communication skills and assessment can be beneficial for the learners as it gives them learning opportunities under a controlled environment.

Objectives: 1 . To assess the improvement in communication skills with the use of simulated patients after communication skills training. 2. To obtain feedback from simulated patients about patient satisfaction. 3. To obtain feedback from students and faculties about communication skills training intervention and simulated patients for assessment.

Methods: After a thorough introduction and explanation of the study, out of total of 139 students from the fifth-semester bachelor of medicine and bachelor of surgery (MBBS), 44 students gave the willingness to participate. Students were divided into two groups of 22 students; one group acted as doctors, and the other group acted as a standardized patient group. Each simulated patient was randomly assigned to one doctor to make a pair; thus, 22 random pairs of doctor and patients were formed. Before and after giving communication skills training, each doctor-patient pair's consultation was analyzed for clinical communication skills using the Kalamazoo scale adapted version by trained observers. After each consultation, each patient was given a patient satisfaction questionnaire to fill.

Results: In this study, students were improved significantly in each competency of the Kalamazoo scale after communication skills training. Before giving this training, the total mean communication skills score of students was 49.86 ( $S D=10.73$ ), and after training, it significantly improved to $75.45(\mathrm{SD}=15.78)(\mathrm{P}<0.05)$. Before the training, the mean patient's satisfaction score was 48.95 ( $\mathrm{SD}=12.18)$, which significantly improved after training to $60.36(\mathrm{SD}=3.99)(\mathrm{P}<0.05)$. Students as well as observers, found the Kalamazoo scale very useful for communication skills training and assessment. In feedback, they mentioned that the simulated patient approach for the assessment of communication skills was useful.

Conclusions: This study showed that the clinical communication skills training with a structured scale was helpful for medical students. Students were found interested in learning such new skills; thus, clinical communication skills training should be an integral part of medical education. Simulated patients were found useful and can be used for the assessment of other clinical skills in medical education.
\end{abstract}

Keywords: Communication Skills, Simulated Patients, Calagary Cambridge Communication Skills Guide, Kalamazoo Scale Adapted Version

\section{Background}

For a medical practitioner, good communication skill is equally important as medical knowledge. Good communication skill is beneficial for the development of rapport with patients, which leads to better diagnosis and treatment. Communication skill is linked to faster recovery, discharge from hospital, adherence to analgesics, and patient satisfaction. It also affects biological, psychological, and social outcomes (1-4).

On the contrary, bad communication skills increase medical errors, complications, less compliance, and various legal issues. A study conducted in a European nation mentioned patients who were not involved in decision making, and it affected the outcome of the patients adversely (5).

In India, the regulatory body for medical education has introduced the Competency-Based Medical Education

Copyright (c) 2020, Journal of Medical Education. This is an open-access article distributed under the terms of the Creative Commons Attribution-NonCommercial 4.0 International License (http://creativecommons.org/licenses/by-nc/4.0/) which permits copy and redistribute the material just in noncommercial usages, provided the original work is properly cited. 
(CBME; 2019) recently. It has incorporated communication skills as soft skills to be taught to undergraduate medical students as a part of the curriculum. A separate module in the curriculum under the CBME is AETCOM (Attitude, Ethics, and Communication) module, through which relevant soft skills are taught to undergraduate medical students under different phases of teaching (6).

Various medical state licensing examinations in the western world, such as the Professional and Linguistic Assessment Board (PLAB) test and the United States Medical Licensing Examination (USMLE) have also introduced communication skills assessment. The General Medical Council (GMC) in London and the Academy of Royal Medical colleges has also given importance to communication skills training and assessment (3).

In Indian medical colleges, clinical teaching is mainly at the bedside with direct patient contact. In recent times, clinical teaching and assessment are developed through simulated patients with several benefits. The simulated patient's concept was first introduced to us by Barrows and Abrahamson in 1960 (7). Simulated patients can be laymen who are trained for different clinical conditions through script and role-play.

With simulated patients, medical students can be taught soft skills of communication in a controlled environment before exposing them to real-life conditions. Another advantage is that simulated patients can give valuable feedback, which can also be helpful for improving the communication skills of students. Simulated patients will be helpful for teaching as well as the assessment of communication skills $(8,9)$. Such simulated patients are not commonly used for the assessment of communication skills in India. Therefore, this study was undertaken to assess the improvement in communication skills of undergraduate medical students with the aid of simulated patients. Such a study can act as a baseline for future largerscale implementation that can be undertaken if such intervention is found to be helpful in improving the communication skills of future medical practitioners.

\section{Objectives}

Accordingly, the main objectives of this study were:

1. To assess the improvement in communication skills with the use of simulated patients after communication skills training.

2. To obtain feedback from simulated patients about patient satisfaction.

3. To obtain feedback from students and faculties about communication skills training intervention and simulated patients for assessment.

\section{Methods}

This interventional study was carried out from April 2018 to August 2018 at GMERS Medical College Valsad. The study was started after obtaining permission from the Institutional Human Ethics Committee.

In this study, 139 students from the fifth semester (bachelor of medicine and bachelor of surgery) MBBS were explained about the study. Out of these, 44 students showed willingness and were included in the study. The study was started after obtaining written informed consent. Students were divided into two groups of 22 students; one group acted as doctors, and the other group acted as simulated patients.

Five common clinical conditions, such as hypertension, diabetes, migraine, acute gastroenteritis, and malaria, were identified after consultation with clinicians. The patient group was given training with written script in local language as well as role-play by the investigator about these clinical conditions. The patient group performed before the investigators for the improvement as needed before implementing the final study. Now each patient was randomly assigned to one doctor to make a pair; thus, 22 random pairs of doctors and patients were made.

Another session was organized for all students who participated in this study to sensitize them about the importance of clinical communication skills in medical practice. The investigator explained thoroughly the importance of communication skills and also discussed the Calgary-Cambridge Guide (C-CG) in detail (10).

Then, the role-play was performed by faculties, demonstrating the importance of good and bad clinical communication skills. Few videos were shown to students about communication skills. The investigator gave them an idea about various scales used for communication skills training and assessment, such as the Kalamazoo scale, SEGUE (set the stage, elicit information, give information, understand the patient's perspective, and the encounter) scale, and C-CG. The last session was ended with student queries. There were five observers from the department responsible for the study. The observers were also trained by the investigator team through presentation and role-play. The observer provided a printed Essential Elements Communication Checklist (Adapted) (KEECC-A) for study, and any query regarding assessment through the scale was solved (11).

Before and after giving communication skills training, each doctor-patient pair's consultation was analyzed for clinical communication skills using KEECC-A by a trained observer. After each consultation, each patient was given a patient satisfaction questionnaire to fill. Patient's percep- 
tion about the doctor was analyzed by a 14-point patient satisfaction scale (containing 14 items scoring from 1 to 5 score; total score: 14 to 70 ) by patients. The doctor's communication skills were analyzed by a trained observer using a 7-point Kalamazoo scale adapted version, which contained 24 items. After giving communication skills training, changes in doctor's communication skills, the total score, as well as the patient satisfaction total score were analyzed by the paired t-test using MS EXCEL (Figure 1).

\section{Results}

In this study, KEECC-A (11) was used. This clinical communication skills checklist contains an assessment of 7 competencies, like A. Building a relationship with the patient (4 sub-competencies), B. Opening the discussion with the patient (3 sub-competencies), C. Gathering relevant information from the patient (4 sub-competencies), D. Understanding the patient's perspective about the clinical condition (2 sub-competencies), E. Sharing information with the patient regarding clinical condition (3 subcompetencies), F. Reaching the agreement with patient regarding a new or changed plan of investigation and treatment (4 sub-competencies), and G. Providing closure of meeting with a summary and clarification of the patient's query (4 sub-competencies). Thus, a total of 24 competencies (each competency scored 1 to 5; a total score of 24 to 120). In this study, students improved significantly in most of the competencies after communication skills training. Students were aware of asking patients about "Is there anything else?" to elicit a full set of concerns and can explain properly the agenda for visiting the doctor. Thus, for these competencies, the difference was not statistically significant (Table 1).

Before giving communication skills training, the total mean communication skills score of students was 49.86 (10.73), and after training, that significantly improved to 75.45 (15.78) $(\mathrm{P}<0.05)$. Most of the students were not aware of such scales and training in communication skills. Before communication skills training, the mean patient's satisfaction score was 48.95 (12.18), which significantly improved after training to $60.36(3.99)(\mathrm{P}<0.05)$. This showed that with improvement in patient satisfaction, is also increased, which can lead to increased compliance with therapy.

\section{Discussion}

Good communication skill is beneficial for patient, doctor, and community. It also improves the patient's understanding and better recall of information. Better communication will lead to better doctor-patient relationships; thus, it helps retrieve information from the patient and leads to better diagnosis. Through good communication, patient's views are taken into consideration in the mutual decision process. Sensible communication is also helpful to prevent clinical and medicine errors (5, 12-14). For doctors, good communication will increase confidence and job satisfaction. Doctors can very well deal with emotional conditions through good communication skills. It also reduces cases of doctors being sued by patient (15).

In this study, the doctor's communication skills significantly improved after clinical communication skills training. Regarding all the competencies, in most of the competencies, students improved. It was also correlated well with improvement in patient satisfaction level. Other studies also supported similar results (3). One study mentioned that lack of time, gender difference, cultural norms, and lack of training were the main hurdles in effective communication skills (16). In our study, it was found that lack of time and lack of training are major reasons for not having effective communication skills. Communication skills are soft skills, which will take time and effort to develop, and it will require continuous sessions to improve communication skills.

After the study, we received feedback from the students about this intervention, and all the students found it interesting. They also liked the simulated patient approach for the assessment of communication skills. They proposed that such type of training should be done frequently and should be incorporated into teaching. Students from other semesters of MBBS also wished to participate in such training in the future. Therefore, with the help of interested faculties, we planned to organize such training for all the medical students of the college. The simulated patient has a lot of advantages in medical education to teach and assess history taking, physical examination, and communication skills (8). Students found that C-CG and other scales were very much helpful in improving clinical communication skills. Our trained observer was also given feedback that the KEECC-A was very well structured to assess communication skills. They also found the simulated patient approach for communication skills assessment very helpful. One review of simulated patient effectiveness mentioned that it is useful to achieve technical, non-technical, cognitive, and other skills. Thus, the simulated patient approach is quite useful to achieve clinical competencies of medical education (17).

We planned to incorporate clinical communication skills training with role-playing and hands-on training by simulated patients in the undergraduate medical curriculum of our institute. Future studies can be planned with the simulated patients for other skills, such as history tak- 


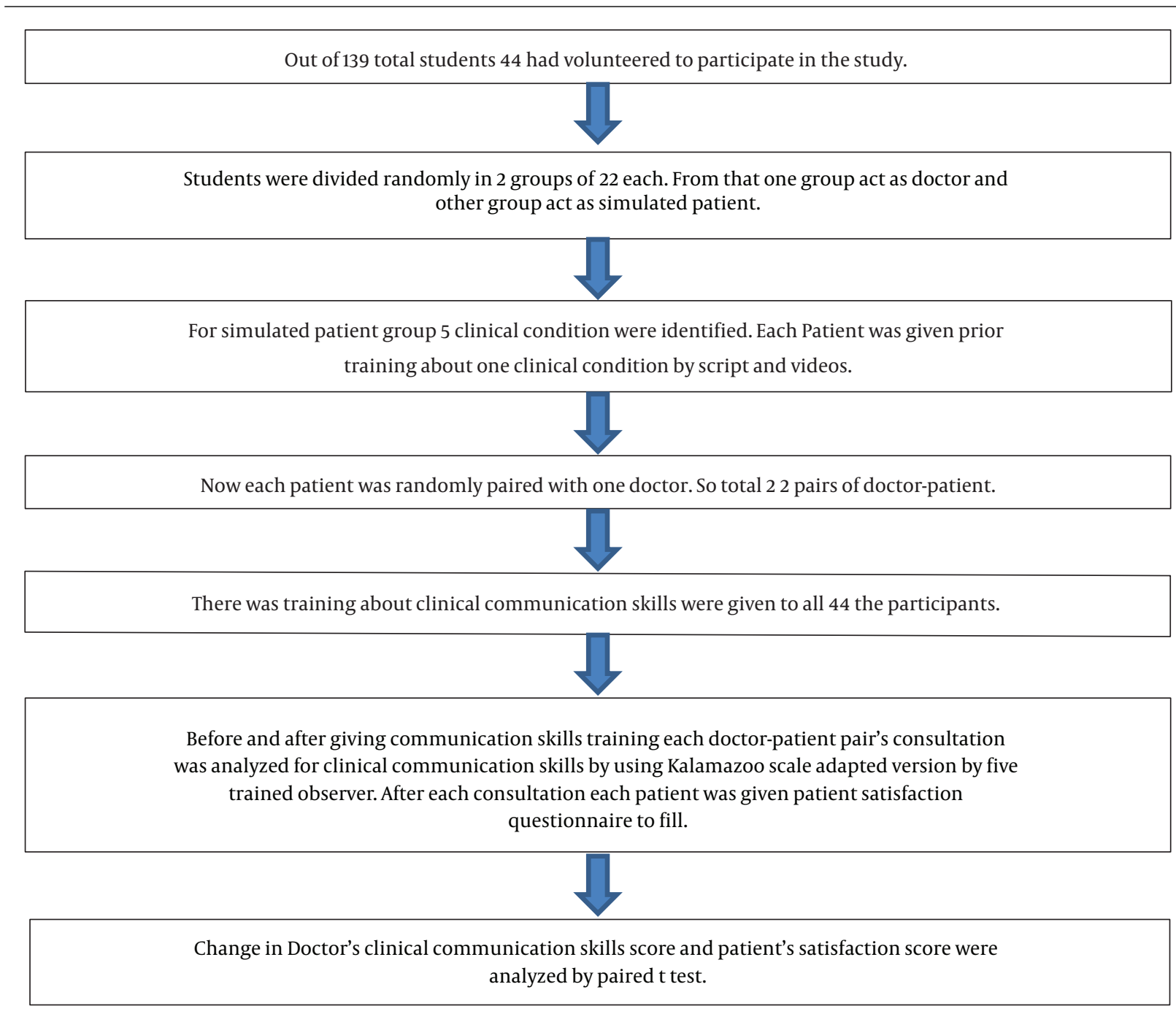

Figure 1. Study design flow chart

ing, clinical examination, etc. There were few studies in which the standard and quality criteria are followed while preparing the simulated patient for the assessment purpose, which will guide future research $(9,18)$.

\subsection{Conclusion}

Training clinical communication skills were found to be helpful in improving the communication skills of undergraduate medical students. Training with the help of structured scales facilitate the learning process. A simulated patient approach was found as a helpful and interesting tool for the assessment of communication skills. Therefore, incorporating such training within the medical curriculum needs to be encouraged. Effective use of simulated patients for various skills assessment in medical education will be promoted.

\section{Acknowledgments}

We are thankful to Calhoun Aaron for giving permission to use KEECC-A. We are very thankful to the Department of Pharmacology and Medical Education Unit of GMERS Medical College Valsad for their support in this study. This study was done as a part of the Advance Medical Education Course at G. S. Medical College and KEM Hospital. We are thankful to the faculties of the Medical Education Department of G. S. Medical College and KEM Hospital Mumbai for their guidance and support. 


\begin{tabular}{|c|c|c|c|c|}
\hline No & $\begin{array}{c}\text { Communication skills competency according to Kalamazoo checklist adapted } \\
\text { version }\end{array}$ & Before training Mean (SD) & After training Mean (SD) & PValue \\
\hline \multicolumn{5}{|c|}{ A. Builds a Relationship (includes the following) } \\
\hline $\mathbf{1}$ & Greets and showing interest in the patient as a person & $2.5(0.99)$ & $3.64(0.93)$ & 0.0001 \\
\hline 2 & Using words that show care and concern throughout the interview & $2.23(0.95)$ & $3.36(0.77)$ & 0 \\
\hline 3 & Using tone, pace, eye contact, and posture that show care and concern & $2.82(0.83)$ & $3.68(0.7)$ & 0.0001 \\
\hline 4 & Responding explicitly to patient's statements about ideas and feelings & $2.09(0.67)$ & $2.95(0.98)$ & 0.003 \\
\hline \multicolumn{5}{|c|}{ B. Opens the Discussion (includes the following) } \\
\hline 5 & Allowing the patient to complete opening statement without interruption & $2.27(0.69)$ & $3.68(0.47)$ & 0 \\
\hline 6 & Asking "Is there anything else?" to elicit a full set of concerns & $2.95(0.82)$ & $3.41(0.89)$ & 0.0763 \\
\hline 7 & Explaining and/or negotiating an agenda for the visit & $2.09(0.73)$ & $2.45(1.12)$ & 0.225 \\
\hline \multicolumn{5}{|c|}{ C. Gathering Information (including the following) } \\
\hline 8 & Begining with patient's story using open-ended questions (e.g. "tell me about...") & $2.73(1.01)$ & $3.64(0.48)$ & 0 \\
\hline 9 & Clarifying details as necessary with more specific or "yes/no" questions & $2.41(0.78)$ & $3.73(0.69)$ & 0 \\
\hline 10 & Summarizing and giving patient opportunity to correct or add information & $2.09(0.85)$ & $3.09(1.16)$ & 0.0102 \\
\hline 11 & Transitions effectively to additional questions & $2.05(0.71)$ & $2.95(0.82)$ & 0.0013 \\
\hline \multicolumn{5}{|c|}{ D. Understanding the Patient's Perspective (including the following) } \\
\hline 12 & Asking about life events, circumstances, other people that might affect health & $2.45(0.99)$ & $3(1.04)$ & 0.0246 \\
\hline 13 & Asking patient's beliefs, concerns, and expectations about illness and treatment & $2.05(0.93)$ & $2.73(0.96)$ & 0.0125 \\
\hline \multicolumn{5}{|c|}{ E. Sharing Information (including the following) } \\
\hline 14 & Assesses patient's understanding of problem and desire for more information & $2(0.90)$ & $3.32(1.1)$ & 0.0001 \\
\hline 15 & Explaining using words that patient can understand & $2.91(1)$ & $3.73(0.62)$ & 0.001 \\
\hline 16 & Asking if the patient has any questions & $1.86(0.69)$ & $2.5(1.12)$ & 0.0312 \\
\hline \multicolumn{5}{|c|}{ F. Reaching an Agreement (if new/changed plan) (including the following) } \\
\hline 17 & Including patient in choices and decisions to the extent s/he desires & $1.77(0.79)$ & $3.32(1.06)$ & 0 \\
\hline 18 & Checking for mutual understanding of diagnostic and/or treatment plans & $1.59(0.58)$ & $3.14(1.01)$ & 0 \\
\hline 19 & Asking about patients ability to follow diagnostic and/or treatment plans & $1.5(0.5)$ & $3.09(1.2)$ & 0 \\
\hline 20 & Identifying additional resources as appropriate & $1.32(0.55)$ & $2.45(1.23)$ & 0.0005 \\
\hline \multicolumn{5}{|c|}{ G. Providing Closure (including the following) } \\
\hline 21 & Asking if patient has questions, concerns, or other issues & $1.55(0.66)$ & $2.64(0.98)$ & 0.0001 \\
\hline 22 & Summarizing & $1.36(0.57)$ & $3.18(1.34)$ & 0 \\
\hline 23 & Clarifying the follow-up or contact arrangements & $1.91(0.67)$ & $3.27(0.75)$ & 0 \\
\hline \multirow[t]{2}{*}{24} & Acknowledging patient and closes interview & $1.36(0.64)$ & $2.5(1.03)$ & 0.0006 \\
\hline & Total score & $49.9(10.5)$ & $75.5(15.4)$ & 0 \\
\hline
\end{tabular}

\section{Footnotes}

Authors' Contribution: Study concept and design: N.C., P.S., J.D., A.S. N.P., and S.B.; analysis and interpretation of data: N.C., P.S., J.D., N.P., S. B., and A.S.; drafting of the manuscript: N.C., P.S., J.D., A.S., S.B. and N. P.; critical revision of the manuscript for important intellectual content: N.C., P.S., J.D. S.B., N.P. and A.S.; statistical analysis: N.C., P.S., J.D, A.S. N.P., and S.B.; Administrative, technical, and material support: N.C., P.S., J.D., N.P., S.B., and A.S. Study supervision: N.C., P.S., J.D., N.P., A.S., S.B.

Conflict of Interests: None decalred.

Ethical Approval: The study was started after obtaining permission from the Institutional Human Ethics Committee.

Funding/Support: None declared.

Informed Consent: Informed consent was taken from 
the participants.

\section{References}

1. Haidet P, Dains JE, Paterniti DA, Hechtel L, Chang T, Tseng E, et al. Medical student attitudes toward the doctor-patient relationship. Med Educ. 2002;36(6):568-74. doi: 10.1046/j.1365-2923.2002.01233.x. [PubMed: 12047673].

2. Cegala DJ, Lenzmeier Broz S. Physician communication skills training: a review of theoretical backgrounds, objectives and skills. Med Educ. 2002;36(11):1004-16. doi: 10.1046/j.1365-2923.2002.01331.x. [PubMed: 12406260].

3. Brown JB, Boles M, Mullooly JP, Levinson W. Effect of clinician communication skills training on patient satisfaction. A randomized, controlled trial. Ann Intern Med.1999;131(11):822-9. doi: 10.7326/0003-4819131-11-199912070-00004. [PubMed: 10610626].

4. Ong LML, de Haes JCJM, Hoos AM, Lammes FB. Doctor-patient communication: A review of the literature. Social Science \& Medicine. 1995;40(7):903-18. doi: 10.1016/0277-9536(94)00155-m.

5. National Health Service in Scotland; Centre for Change Innovation. Talking matters Developing the communication skills of doctors. Edinburgh (United Kingdom): Scottish Executive; 2003.

6. Attitude Ethics and Communication (AETCOM). Competencies for the Indian Medical Graduate. 2018, [cited 15 November 2020]. Available from: https://www.nmc.org.in/information-desk/for-colleges/ ug-curriculum.

7. Barrows HS, Abrahamson S. The programmed patient: a technique for appraising student performance in clinical neurology. Academic Medicine. 1964;39(8):802-5.

8. Beigzadeh A, Bahmanbijari B, Sharifpoor E, Rahimi M. Standardized patients versus simulated patients in medical education: are they the same or different. Journal of Emergency Practice and Trauma. 2015;2(1):25-8. doi: 10.15171/jept.2015.05.

9. Cleland JA, Abe K, Rethans JJ. The use of simulated patients in medical education: AMEE Guide No 42. Med Teach. 2009;31(6):477-86. doi: 10.1080/01421590903002821. [PubMed: 19811162].
10. Kurtz SM, Silverman JD. The Calgary-Cambridge Referenced Observation Guides: an aid to defining the curriculum and organizing the teaching in communication training programmes. Med Educ.1996;30(2):83-9. doi:10.1111/j.1365-2923.1996.tb00724.x. [PubMed: 8736242].

11. Peterson EB, Calhoun AW, Rider EA. The reliability of a modified Kalamazoo Consensus Statement Checklist for assessing the communication skills of multidisciplinary clinicians in the simulated environment. Patient Educ Couns. 2014;96(3):411-8. doi: 10.1016/j.pec.2014.07.013. [PubMed: 25103180].

12. Maguire P, Pitceathly C. Key communication skills and how to acquire them. BMJ. 2002;325(7366):697-700. doi: 10.1136/bmj.325.7366.697. [PubMed: 12351365]. [PubMed Central: PMC1124224].

13. Hulsman RL, Ros WJ, Winnubst JA, Bensing JM. The effectiveness of a computer-assisted instruction programme on communication skills of medical specialists in oncology. Med Educ. 2002;36(2):125-34. doi: 10.1046/j.1365-2923.2002.01074.x. [PubMed: 11869439].

14. Meryn S. Improving doctor-patient communication. Not an option, but a necessity. BMJ.1998;316(7149):1922. doi:10.1136/bmj.316.7149.1922. [PubMed: 9641926]. [PubMed Central: PMC1113402].

15. Feinmann J. Brushing up on doctors' communication skills. The Lancet. 2002;360(9345):1572. doi: 10.1016/s0140-6736(02)11592-3.

16. Abdulrahman KA. WHAT DO PATIENT's EXPECT OF THEIR GENERAL PRACTITIONERS? J Family Community Med. 2003;10(1):39-45. [PubMed: 23011979]. [PubMed Central: PMC3425756].

17. Williams B, Song JJY. Are simulated patients effective in facilitating development of clinical competence for healthcare students? A scoping review. Adv Simul (Lond). 2016;1:6. doi: 10.1186/s41077-016-0006-1. [PubMed: 29449975]. [PubMed Central: PMC5796606].

18. Peters T, Sommer M, Fritz AH, Kursch A, Thrien C. Minimum standards and development perspectives for the use of simulated patients - a position paper of the committee for simulated patients of the German Association for Medical Education. GMS J Med Educ. 2019;36(3):Doc31. doi: 10.3205/zma001239. [PubMed: 31211226]. [PubMed Central: PMC6545616]. 